\title{
Bright tongue sign: a diagnostic marker for amyotrophic lateral sclerosis
}

Sinal da língua brilhante: um marcador diagnóstico para esclerose lateral amiotrófica

Paulo Victor Sgobbi de Souza, Wladimir Bocca Vieira de Rezende Pinto, Acary Souza Bulle Oliveira

A 53-year-old woman complained about a 2-year-history of progressive tetraparesia with global brisk reflexes, global amyotrophy and fasciculations. As her clinical picture suggested a motor neuron disease, she performed electroneuromyography (ENMG) unvealing anterior horn compromise and brain MRI study with the so-called "bright tongue sign" (Figure), in this context suggestive of amyotrophic lateral sclerosis (ALS). ALS represents the most common form of neurodegenerative motor neuron disease ${ }^{2}$. Although clinical and ENMG findings are highly suspicious, neuroimaging studies commonly present with typical features representing compromise of pyramidal tracts ${ }^{3}$, sometimes with signs of fatty replacement in the chronic denervated target musculature ${ }^{1}$.
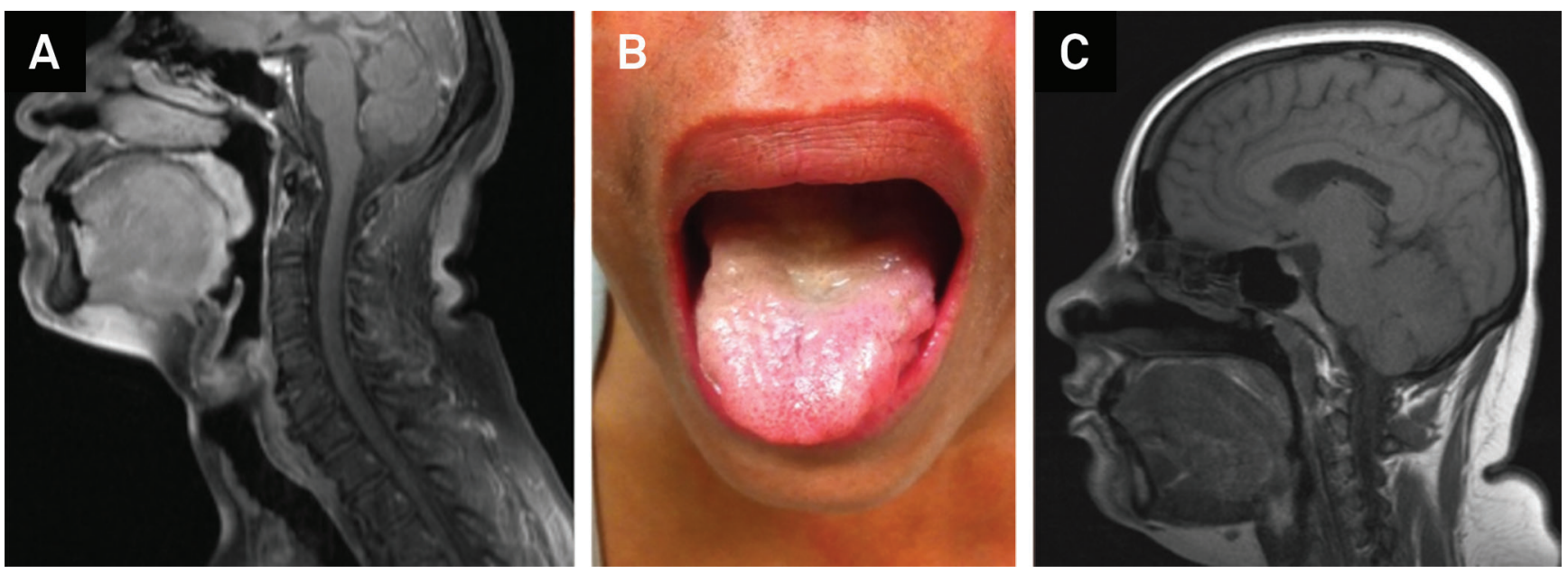

Figure. Sagittal T1-weighted brain MRI discloses abnormal diffuse hyperintensity of the tongue musculature (A), correspondent to severe atrophic tongue (B). Normal tongue MRI feature is showed (C).

Fox MD, Cohen AB. “Bright tongue sign” in ALS. Neurology 2012;79:1520.

2. Oliveira AS, Pereira RD. Amyotrophic lateral sclerosis (ALS): three letters that change the people's life. Forever. Arq Neuropsiquiatr 2009;67:750-782.
3. Agosta F, Chiò A, Cosottini $M$, et al. The present and future of
neuroimaging in amyotrophic lateral sclerosis. AJNR Am J Neuroradiol 2010;31:1769-1777.

Unidade Neuromuscular, Departamento de Neurologia, Universidade Federal de São Paulo, Sao Paulo SP, Brazil.

Correspondence: Wladimir Bocca Vieira de Rezende Pinto; Rua Botucatu, 740; 04023-900 São Paulo SP, Brasil; E-mail: wladimirbvrpinto@gmail.com Conflict of interests: There is no conflict of interest to declare.

Received 17 March 2014; Received in final form 17 April 2014; Accepted 07 May 2014. 